\title{
GRASSLANDS G 4710 TALL FESCUE FESTUCA ARUNDINACEA (SCHREB.)
}

\author{
L. B. Anderson
}

Grasslands Division, DSIR, Palmerston N orth

GrassLands 4710 (G4710) is an experimental cultivar of tall fescue, Festuca arundinacea (Sohreb.), developed by Grasslands Division for use in New Zealand pastures.

Following hybridization among selected plants from Australia, Israel, U.S.A., North Africa and wild New Zealand populations, two cycles of recurrent selections for yield, persistence and disease resistance were carried out. The first phase of the programme involved two years at Palmerston North and Lincoln, the second involving a further two years at Palmerston North. Both phases were carried out by A. J. McNeur, formerly of Grasslands Division.

A third cycle of selection followed a two-year spaced planet progeny test at Palmerston North and included selection for low leaf tensile strength (Evans, 1964) . Among ryegrass strains it had been demonstrated that led strength was negatively correlated with weight gains in sheep (Rae et al., 1964). This parameter was therefore 'included in an attempt to improve the nutritive value of the selected population. The resulting population, which lacked any plant material of New Zealand origin, formed the basis of the experimental cultivar, G47 10.

By comparison with the United Kingdom variety S170, G4710 has a more lax growth habit, is lighter green in colour, and is later flowering. Annual production is similar to that of S170 (usually about $15 \mathrm{t} / \mathrm{ha}$ in mown swards at Palmerston North) . Any seasonal differences have favoured G4710 in the late autumn and early winter and S1 70 in spring.

Recent experimental evidence from observations of grazing sheep indicated that more herbage was eaten from G4710 than S170 plots. Observations on both sheep and cattle have suggested that G47 10 is more acceptable to stock than S 170 .

Observations on disease infection among spaced plants at both Palmerston North and Lincoln regional station have shown that G4710 was more resistant to rust and other Pasture diseases than was S170. Similar observations have been made on mown swards at Palmerston North. 
Breeding programmes to try to effect further improvements of G4710 are still continuing at Grasslands Division.

The evidence so far obtained from trials suggests that Grasslands 4710 could be a more useful cultivar of tall fescue than S170 under many conditions in New Zealand where tall fescue may be grown.

\section{REFERENCES}

Evans, P., 1964: A study of leaf strength in four ryegrass varieties. N.Z. $J l$ agric. Res., 7: 508.

Rae, A. L.; Brougham, R. W.; Bärton, R. A., 1964: A note on liveweight gains of sheep grazing different ryegrass pastures. N.Z. $/ l$ agric. Res., 7: 491 . 